\title{
El Parlamento andaluz aprueba la nueva ley de patrimonio cultural
}

El pasado 14 de noviembre el Parlamento de Andalucía aprobó por 88 votos a favor, 5 abstenciones y ningún voto en contra, el nuevo marco normativo del patrimonio histórico en Andalucía, convirtiéndose en la primera Comunidad Autónoma en revisar su legislación en esta materia. Esta nueva norma nace con dos objetivos fundamentales: incorporar los nuevos conceptos que la doctrina patrimonial ha ido asentando, y mejorar aspectos de su gestión tras la experiencia de dieciséis años de aplicación de la Ley de Patrimonio Histórico de Andalucía de 1991.

\section{+ INFO}

Texto normativo publicado en BOJA número 248, de 19 de diciembre de 2007

http://andaluciajunta.es/portal/boletines/2007/12/ aj-bojaVerPagina-2007-12/0,,bi=698330292882,00.html
A estos objetivos se suman la necesaria adecuación y armonización con otras legislaciones sectoriales de gran incidencia en el patrimonio histórico que también han sido creadas o revisadas: legislación del suelo, procedimientos administrativos, penal, igualdad de género..., así como la oportunidad de integrar en un solo texto legal el marco normativo de la legislación autonómica y estatal en materia de patrimonio histórico ${ }^{1}$.

La norma incorpora, sin renunciar a lo ya existente, nuevas figuras y estrategias en materia de protección, conservación, investigación y difusión del patrimonio histórico, reconociendo expresamente el importante papel que desempeñan las corporaciones locales en dicha materia, de manera especial a través de la redacción de sus normas urbanísticas.

Entre las novedades figura la creación del "Inventario de Bienes Reconocidos Patrimonio Histórico Andaluz", instrumento independiente y complementario del "Catálogo General del Patrimonio Histórico Andaluz", cuya finalidad es facilitar la identificación de los bienes

(- Los Millares (Almería) / JUAn CARLos CAZALLA, IAPH

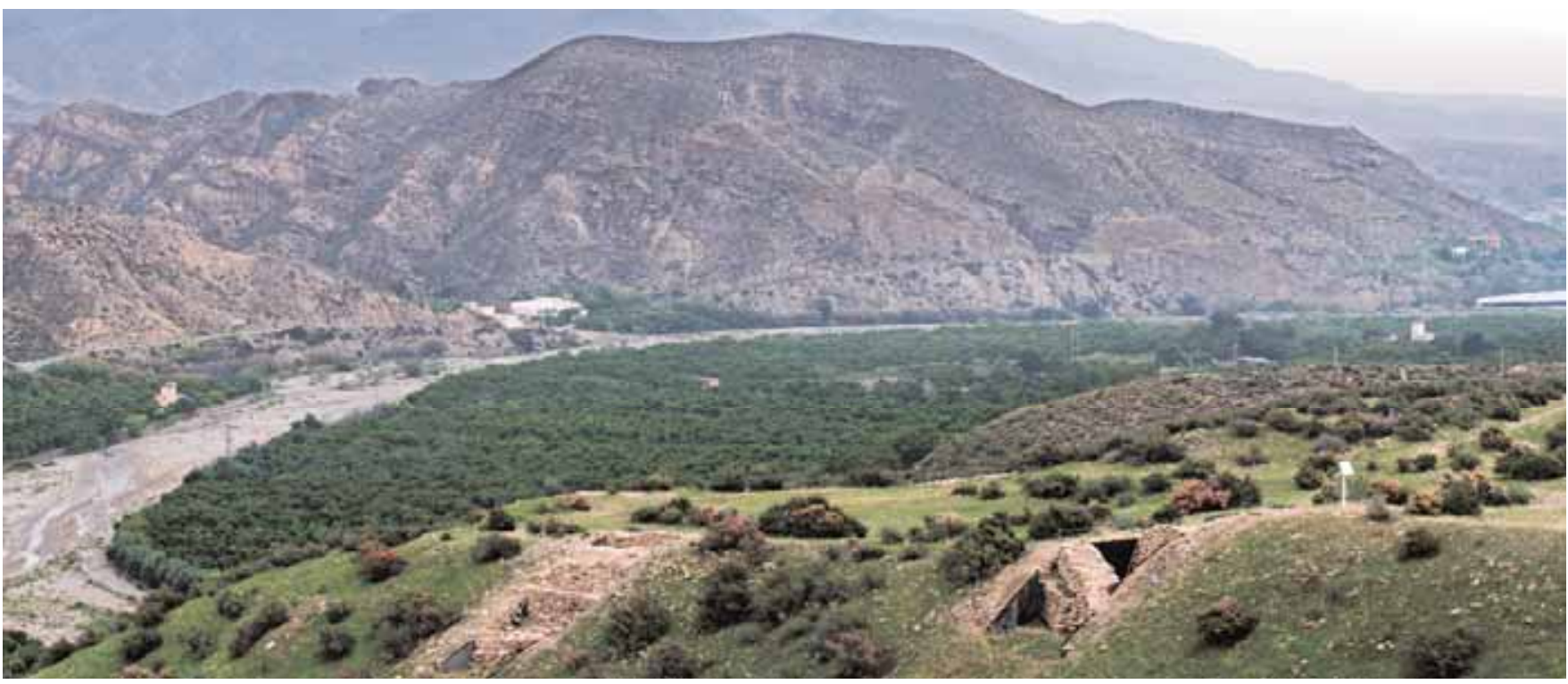


inmuebles del patrimonio histórico de Andalucía no incluidos en el CGPHA, y asegurar su inclusión en los Catálogos Urbanísticos.

También se reforma la estructura del CGPHA que pasa a ser integrado por los "Bienes de Interés Cultural", que pueden llevar Instrucciones Particulares y sus actuaciones requieren autorización previa de la administración cultural, los "Bienes de Catalogación General" de los que la administración debe tener conocimiento previo de sus actuaciones y puede proponer medidas correctoras, y los bienes incluidos en el "Inventario General de Bienes Muebles" establecido en la Ley 16/1985 del Patrimonio Histórico Español.

Se incorporan medidas agilizadoras en materia de protección del patrimonio histórico como el establecimiento de entornos "automáticos" por ministerio de ley para los Bienes de Interés Cultural inmuebles que aún no lo poseen, y la inscripción directa en el CGPHA de los bienes del patrimonio histórico incluidos en el Inventario de Bienes Muebles de la Iglesia Católica, así como de los que se encuentren en posesión de la Administración de la Junta de Andalucía, las entidades locales y las universidades.

El Patrimonio Industrial adquiere entidad singular dedicándosele un Título propio y la introducción de la figura de protección de "Lugar de Interés Industrial".

Otra de las novedades más significativas es la creación dentro de las tipologías inmuebles de Bienes de Interés Cultural de las "Zonas Patrimoniales". Esta figura está pensada para la protección de territorios o espacios que constituyan un conjunto patrimonial, diverso y complementario, integrado por bienes diacrónicos representativos de la evolución humana. Las Zonas Patrimoniales pueden dar lugar a los "Parques Culturales", institución del patrimonio histórico en cuyo órgano de gestión participan las Administraciones y sectores implicados.

En materia de patrimonio arqueológico se regula, por primera vez, el uso de detectores de

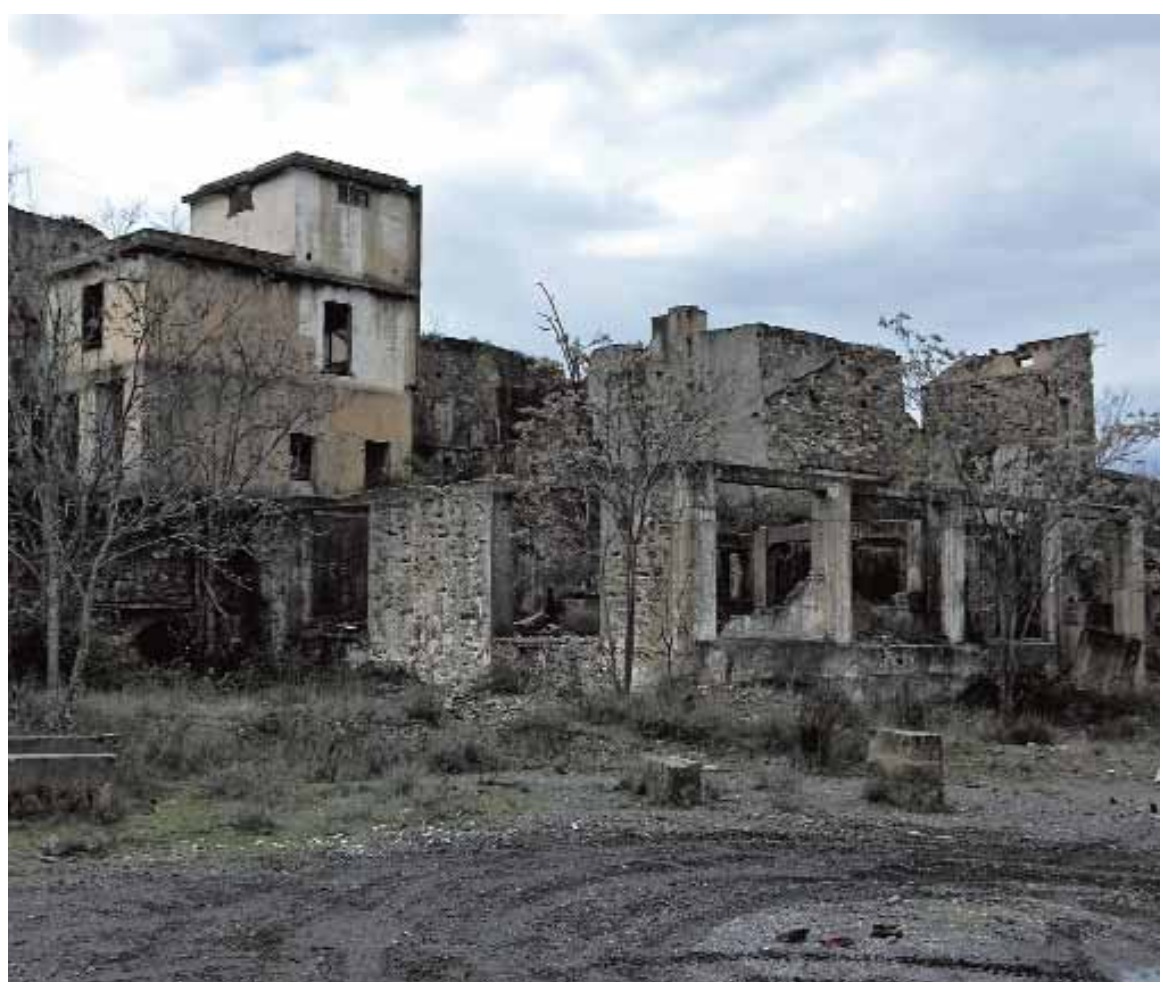

(1) Distrito minero Linares-La Carolina (Jaén) / JAVIER RomeRo, IAPH

metales, se establece la presunción del carácter demanial de los objetos y restos materiales integrantes del patrimonio arqueológico que no sean comunicados en el plazo de un año, y la obligación de contar en los planes urbanísticos de un análisis arqueológico de los suelos a transformar: suelo urbanizable, sistemas generales y suelo urbano no consolidado.

Se avanza en la protección de los entornos de los Bienes de Interés Cultural estableciéndose medidas para evitar su contaminación visual o perceptiva. Los Ayuntamientos deberán de contar con planes de descontaminación visual o perceptiva de su patrimonio histórico, y los titulares de las instalaciones contaminantes deberán retirarlos en un plazo determinado a su costa.

Con respecto al planeamiento de protección la ley establece contenidos mínimos y un nuevo procedimiento para su convalidación así como la necesidad de contar los Ayuntamientos con una Comisión Técnica Municipal multidisciplinar que valore las licencias.
También se incide en los "criterios de conservación" y concreta contenidos mínimos del "Proyecto de Conservación" como instrumento de intervención en los bienes inscritos en el CGPHA.

Por último, y sin agotar las novedades introducidas en la nueva ley, se revisa ampliamente el marco de infracciones administrativas y sus sanciones actualizándose las cuantías, que pueden llegar las muy graves hasta el millón de euros.

\section{Juan Manuel Becerra García}

Jefe del Servicio de Protección de la Dirección General de Bienes Culturales. Miembro del equipo de redacción

\section{Nota}

\footnotetext{
${ }^{1}$ Hay que recordar que la Ley $1 / 1991$ del Patrimonio Histórico de Andalucía se encontraba ya redactada cuando se conoce la sentencia 17/1991 del Tribunal Constitucional que restringía de forma drástica las competencias del Estado en materia de patrimonio histórico en favor de las Comunidades Autónomas, por lo que no pudo incorporar dicha circunstancia, aunque sí en los Reglamentos que la desarrollaron.
} 